\title{
ON THE STAR CHROMATIC INDEX OF GENERALIZED PETERSEN GRAPHS
}

\author{
ENQIANG Zhu ${ }^{1,2}$ AND Zehui ShaO \\ Institute of Computing Science and Technology \\ Guangzhou University, Guangzhou 510006, China \\ e-mail: zhuenqiang@gzhu.edu.cn
}

\begin{abstract}
The star $k$-edge-coloring of graph $G$ is a proper edge coloring using $k$ colors such that no path or cycle of length four is bichromatic. The minimum number $k$ for which $G$ admits a star $k$-edge-coloring is called the star chromatic index of $G$, denoted by $\chi_{s}^{\prime}(G)$. Let $\operatorname{GCD}(n, k)$ be the greatest common divisor of $n$ and $k$. In this paper, we give a necessary and sufficient condition of $\chi_{s}^{\prime}(P(n, k))=4$ for a generalized Petersen graph $P(n, k)$ and show that "almost all" generalized Petersen graphs have a star 5-edgecolorings. Furthermore, for any two integers $k$ and $n(\geq 2 k+1)$ such that $\operatorname{GCD}(n, k) \geq 3, P(n, k)$ has a star 5-edge-coloring, with the exception of the case that $\operatorname{GCD}(n, k)=3, k \neq \mathrm{GCD}(n, k)$ and $\frac{n}{3} \equiv 1(\bmod 3)$.
\end{abstract}

Keywords: star edge-coloring, star chromatic index, generalized Petersen graph.

2010 Mathematics Subject Classification: 05C15.

\section{REFERENCES}

[1] M.O. Albertson, G.G. Chappell, H.A. Kierstead, A. Kündgen and R. Ramamurthi, Coloring with no 2-colored $P_{4}$ 's, Electron. J. Combin. 11 (2004) \#R26.

[2] L. Bezegová, B. Lužar, M. Mockovčiaková, R. Soták and R. Škrekovski, Star edge coloring of some classes of grpahs, J. Graph Theory 81 (2016) 73-82. doi:10.1002/jgt.21862

[3] J.A. Bondy and U.S.R. Murty, Graph Theory (Springer, New York, 2008).

\footnotetext{
${ }^{1}$ This work was supported by the National Natural Science Foundation of China under Grants 61672051, 61872101, and the Natural Science Foundation of Guangdong Province under Grant 2018A0303130115.

${ }^{2}$ Corresponding author.
} 
[4] Y. Bu, D.W. Cranston, M. Montassier, A. Raspaud and W. Wang, Star- coloring of sparse graphs, J. Graph Theory 62 (2009) 201-209.

doi:10.1002/jgt.20392

[5] M. Chen, A. Raspaud and W. Wang, 6-star-coloring of subcubic graphs, J. Graph Theory $\mathbf{7 2}$ (2013) 128-145.

doi:10.1002/jgt.21636

[6] Z. Dvořák, B. Mohar and R. Šámal, Star chromatic index, J. Graph Theory 72 (2013) 313-326.

doi:10.1002/jgt.21644

[7] H.A. Kierstead, A. Kündgen and C. Timmons, Star coloring bipartite planar graphs, J. Graph Theory 60 (2009) 1-10. doi:10.1002/jgt.20342

[8] X.S. Liu and K. Deng, An upper bound on the star chromatic index of graphs with $\Delta \geq 7$, J. Lanzhou Univ. Nat. Sci. 44 (2008) 94-95.

[9] M.E. Watkins, A theorem on tait colorings with an application to the generalized Petersen graphs, J. Combin. Theory 6 (1969) 152-164.

doi:10.1016/S0021-9800(69)80116-X

Received 24 October 2017

Revised 27 November 2018

Accepted 28 November 2018 